\title{
Efficacy and tolerability of propolis special extract GH 2002 as a lip balm against herpes labialis: a randomized, double-blind three-arm dose finding study
}

\author{
Simona Holcová ${ }^{\star}$, Marie Hladiková ${ }^{2}$ \\ ${ }^{1}$ Outpatient Department of Dermatovenerology, Brno, Czech Republic; *Corresponding Author: simona.holcova@email.cz \\ ${ }^{2}$ Department for Medical Informatics, 2nd Medical Faculty of the Charles University, Prague, Czech Republic; \\ statistika.hladikova@seznam.cz
}

Received 11 October 2010; revised 17 November 2010; accepted 19 November 2010.

\begin{abstract}
A dose-finding study was performed with respect to the clinical applicability and tolerability of three different concentrations of propolis special extract GH 2002 in a lip balm $(0.1 \%, 0.5 \%$ and $1 \%$ ). The trial was designed as a double-blind, randomized dermatological study in 150 outpatients with Herpes labialis. The primary parameter was the duration in days until painless incrustation in $50 \%$ or $\mathbf{9 0 \%}$ of the patients (observable in 121 patients). Secondary parameters were local pain (assessed on a visual analogue scale), itching, burning and tension/ swelling on a verbal rating scale, and tolerability. Visits were performed on days $2 / 3,5 / 6$ and 8/9. Best efficacy results with shortest healing time (3.4 and 5.4 days in the $50^{\text {th }}$ and $90^{\text {th }}$ percentile, respectively; $p=0.008$ vs. $1 \%$ and 0.09 vs. $0.1 \%$ ) and good tolerability were observed with the $0.5 \%$ concentration. All three concentrations achieved highly significant therapeutic results in comparison with baseline values $(p<0.0005)$ for all secondary parameters as early as day $2 / 3$. Analgesia was the most prominent effect for the patients. Conclusion: The $0.5 \%$ concentration of propolis special extract GH 2002 in a lip balm was found to have the best risk-benefit ratio for the treatment of Herpes labialis.
\end{abstract}

Keywords: Herpes labialis; propolis; lip balm; dose-finding study

\section{INTRODUCTION}

Herpes labialis, generally caused by infection with Herpes simplex type 1 (HSV-1) virus, is characterized by various consecutive stages. An episode begins with a prodromal phase with local pain, tingling and burning, followed by erythematous and papular phases with inflamed and reddened papules, and vesicular phase with fluid-filled blisters. Via the ulceration phase or the bursting of the vesicle with wound formation it finally leads to the incrustation and healing phase [1].

The typical duration of the natural course of an untreated episode of Herpes labialis is seven to fifteen days $[1,2]$. This duration can be significantly reduced to $4.5-6$ days by the topical application of antiviral nucleoside analogues such as aciclovir or penciclovir [2-9]. Both are antimetabolites which inhibit viral replication and thus multiplication in the cell. However, the wide-spread use of nucleoside analogues is associated with the development of resistance [10].

Ultimately, the antiviral effect is only one aspect of treatment. It combats the cause, but the symptoms secondary to the virus infection such as injured and inflamed skin and secondary bacterial infections must not be forgotten. The clinical benefits of nucleoside analogues aciclovir and penciclovir have been critically assessed for the lack of such additional effects $[4,6,9]$. Treatment options with additional antimicrobial and anti-inflammatory effects are clearly welcome.

Propolis, the "bee-glue" from hives, is a natural product with an interesting combination of pharmacological properties, which led to various applications in traditional medicine and naturopathy with documented use over at least two Millennia [11-15]. The broad spectrum of propolis effects is explained by the fact that propolis has the function of protecting the bee-hive against many harmful organisms, such as bacteria, fungi and insects. Modern research with propolis resulted in the description of antimicrobial [15-17], fungicidal [13,18], and anti-inflammatory [19] effects.

Antiviral effects have likewise been described in vitro 
[20-25], and the clinical applicability has been demonstrated with regard to Herpes genitalis (HSV-2) [26]. Among others, flavonoids, caffeic acid ester and cinnamic acid have been described as constituents contributing to the antiviral effect of propolis [22,24,25,27].

Reproducibility of antiviral efficacy requires a standardized product quality due to the regional variability of the chemical composition of propolis. For our clinical research we therefore selected the special extract GH 2002 for which the propolis is exclusively collected in one defined area, and where the composition of the extract is standardized to reproducible contents of flavonoids, polyphenols and phenyl carboxylic acids. In addition, manufacturing involves purification by removal of potentially allergenic waxes and resins, adding to the safety of application.

This same extract GH 2002 has been shown to possess potent time- and concentration-dependent antiviral effects against Herpes simplex virus in vitro $[28,29]$, with a remarkably low $\mathrm{IC}_{50}$ of $2 \times 10^{-5} \%$ against HSV-1, and an $\mathrm{IC}_{50}$ of $4 \times 10^{-4} \%$ against HSV-2. The mechanism of action is not based on antimetabolite effects as with aciclovir and penciclovir, but on a denaturation of the virus membrane.

In an earlier, as yet unpublished study we found a significant therapeutic effect in 150 patients suffering from Herpes labialis after treatment with a lip balm containing $2 \%$ of GH 2002. However, we were not fully convinced of the therapeutic applicability due to the observation of reversible skin irritation with itching and burning in a proportion of the patients exceeding the typical incidence rate of local adverse skin reactions of $2.0-3.8 \%$ with the application of creams containing aciclovir or penciclovir $[2,4,8]$.

The aim of the present dose-finding study was therefore to identify the optimal dose range with respect to efficacy and tolerability. The conclusions shall be applied in a controlled clinical trial which is currently in preparation. We also wanted to examine to what extent the broad biological spectrum of propolis effects, especially the anti-inflammatory and antimicrobial properties, may lead to additional therapeutic benefits in the treatment of Herpes labialis.

\section{PATIENTS AND METHODS}

\subsection{Study Participants}

The study objective was to determine the concentration of propolis extract in a lip balm where the treatment effect against Herpes labialis is still satisfactory and tolerability is acceptable. We also intended to assess the effect of the propolis preparations against symptoms of local irritation, pain, inflammation and wound healing.
The study was performed as a mono-centre, randomized, dose-controlled, three-arm double-blind dose-finding trial.

We selected outpatients presenting to our dermatological practice with an unequivocal diagnosis of Herpes labialis. The number of study participants was chosen to match the number of patients in our earlier study with the application of 2\% propolis special extract GH 2002 in a lip balm $(\mathrm{n}=150)$.

Patients were eligible when they presented themselves within 24 hours after noticing the first prodromal symptoms of Herpes labialis. The exact time when prodromal symptoms were first noted by the patient was documented. Patients could not be included when they had a known allergy against propolis or an excipient of the lip balm, or if they required systemic antiviral treatment. Any local concomitant treatment was excluded, as was systemic medication potentially influencing the immune system, such as corticosteroids, immunosuppressants, methotrexate or cytostatics.

The study was planned and carried out in accordance with the criteria of Good Clinical Practice (GCP) and the ethical standards defined in the declaration of Helsinki. All patients signed an informed consent sheet.

\subsection{Interventions}

The study medication consisted of a lip balm with the active constituent propolis special extract GH 2002. Extract and lip balm were manufactured by Gehrlicher Pharmazeutische Extrakte (Eurasburg, Germany). The propolis extract was embedded in a soft water-in-oil emulsion, without the use of preservatives or dyes. The three study preparations differed only in the concentration of the active constituent $(0.1,0.5$ and $1 \%)$. They were indistinguishable with regard to colour, consistency and external presentation, and were delivered to the study centre in externally identical tubes numbered according to the random list for allocation concealment. Patients were told to apply the lip balm every 2-3 hours, five times daily, to the entire upper and lower lip. No other local preparations including cosmetics were permitted during the study.

\subsection{Randomization and Blinding}

The study participants were allocated to one of three treatment groups according to a pre-prepared random plan. Treatments were blinded for study personnel and monitoring, the patients, the statistician and the sponsor until conclusion of the statistical evaluation.

\subsection{Study Parameters}

The symptoms of Herpes labialis were documented at 
every visit, using the usual classification in prodromal, erythemal, papular, vesicular, erosive and incrusted/healed stages. For each stage the exact time of the occurrence was documented.

Following the first visit, examinations of the patients took place on day 2 or 3 and on day 5 or 6 . A follow-up examination was made on day 8 or 9 for any patients who were not yet healed on day 5/6. The primary assessment parameter was the time between erythemal/papular phase and painless incrustation. The corresponding data was taken from the individual case report forms (CRFs).

The development of pain, itching, tension/swelling and burning were assessed on day $2 / 3$ as secondary parameters. Pain intensity was determined using the internationally accepted visual analogue scale (VAS), in which the patient defines his/her sensation of pain on a scale of $100 \mathrm{~mm}$ between 0 and 100 ( 0 = no pain; $100=$ highest possible pain). The evaluation of the parameters itching, swelling/tension and burning was made on a 4-step verbal rating scale (VRS) $(0=$ nonexistent, $1=$ slight, 2 = moderate, 3 = severe). Finally, local tolerability and any signs of adverse reactions were assessed over the whole treatment period.

\subsection{Statistical Methods}

SPSS v.16.0 was used as the statistical software. Missing values were to be replaced by carrying over the respective last measurement. Statistical methods are indicated with the results for every single evaluation. For testing of the primary parameter in the three treatment groups ( $1 \%$ vs. $0.5 \%$, $1 \%$ vs. $0.1 \%$, and $0.5 \%$ vs. $0.1 \%$ ) the significance level was established with $\mathrm{p}=0.05$, using the Holm-Bonferroni method. Secondary analyses were performed descriptively in all patients with complete data sets (per protocol population).

\section{Results}

150 patients were included into the study. 102 were female (68\%), 48 were male (32\%). The age of the patients was 9 to 81 years (mean $41.6 \pm 16.4$ years, range 9-81). The majority of patients $(n=125 ; 83.3 \%)$ had a history of recurrent Herpes labialis infection with an average of $3.5 \pm 1.7$ episodes per year (range 1-10) for several years. The average duration of an episode was $9.1 \pm 2.0$ days. 25 (16.7\%) of the patients were experiencing Herpes labialis for the first time.

Through the randomization procedure patients were allocated to treatment with $0.1 \%$ propolis extract $(\mathrm{n}=$ 48), $0.5 \%(n=50)$, and $1 \%$ extract $(n=52)$. All 150 patients were available for the visit on treatment day $2 / 3$. Five drop-outs occurred following the examination on study day 2/3: Four patients were excluded due to the observation of local skin reactions (1 patient each of the $0.1 \%$ and $0.5 \%$ groups, and 2 patients from the $1.0 \%$ group). One patient from the $0.1 \%$ group did not come back for the follow-up examinations for unknown reasons. 145 patients continued treatment after day $2 / 3$ ( $\mathrm{n}=$ 46 in the $0.1 \%$ group, $n=49$ in the $0.5 \%$ group, and $n=$ 50 in the $1 \%$ group).

\subsection{Primary Parameter: Time to Painless Incrustation}

121/145 patients were assessable for healing time with painless incrustation, whereas in 24 patients healing occurred with an exfoliative epithelialisation with no incrustation phase. Results correlated well with the observation of secondary parameters (see below). Within this subset of 121/145 patients we calculated the number of days starting from the erythemal/papular phase to complete incrustation of the lesions. The shortest average healing time was found in the $0.5 \%$-group (3.8 \pm 1.5 days), followed by the $0.1 \%$-group (3.9 \pm 1.8 days) and the $1 \%$ group ( $4.9 \pm 1.7$ days).

For the statistical assessment the pre-planned calculation of the time when $50 \%$ and $90 \%$ of patients have reached the incrustation phase $\left(50^{\text {th }}\right.$ and $90^{\text {th }}$ percentile $)$ gives more reliable results. The distribution of patients per group and the corresponding results for healing time are displayed in Figure 1. Shortest healing times were again found in the treatment arm with $0.5 \%$ propolis extract in the lip balm.

The difference between treatment groups was statistically significant (Kruskal-Wallis test: $\mathrm{p}=0.017$ ). The difference between groups was also assessed by pair-wise comparison in the Mann-Whitney test. Whereas for the comparisons between the $0.1 \%$ and the $0.5 \%$ concentration with the $1 \%$ concentration the difference was in both cases statistically significant $(p=0.026$ and 0.008 , respectively), significance was not reached for the comparison between 0.1 and $0.5 \%(p=0.09)$.

In addition to the primary parameter the time from the prodromal phase to complete painless incrustation ( $\mathrm{n}=$ 121) and the time from prodromal symptoms to complete healing in all patients with and without incrustation ( $n=145$ ) was calculated. For the mean healing time the same sequence was confirmed: With the $0.5 \%$ concentration the healing time was $4.8 \pm 1.5$ days $(\mathrm{n}=121)$ and $4.8 \pm 1.8$ days (all patients), respectively. With $0.1 \%$ the respective results were $5.1 \pm 1.8$ and $4.9 \pm 2.0$ days. Finally, the results for the $1.0 \%$-group were $6.1 \pm 1.8$ and $5.8 \pm 2.1$ days, respectively.

Healing was also calculated in the $50^{\text {th }}$ and $90^{\text {th }}$ percentile of each group in all 121 (data not shown) and 145 patients (Figure 2), with very similar findings in both analyses. Again, the difference between treatment groups 


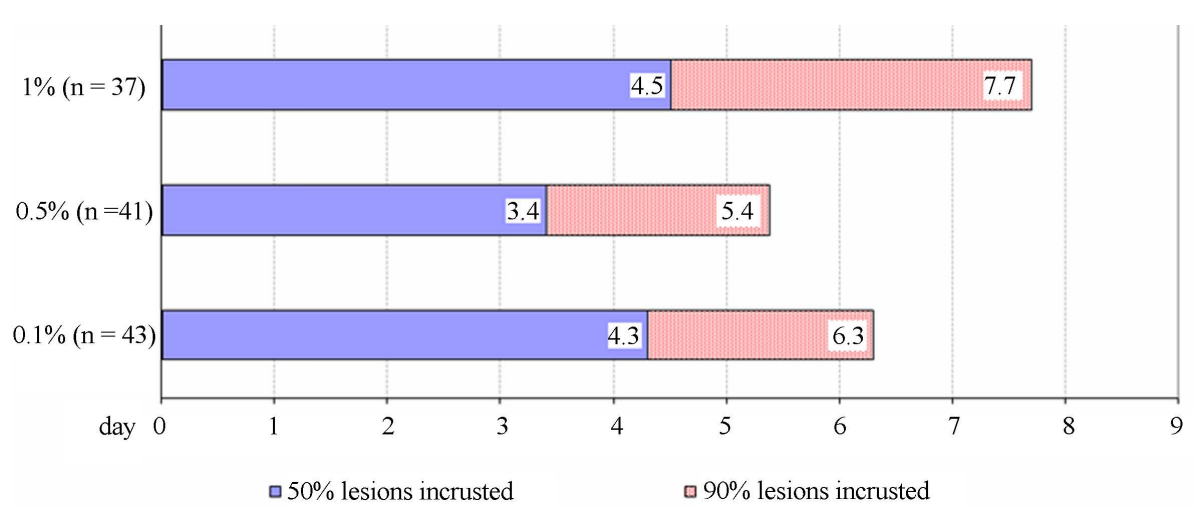

Figure 1. Time from erythemal/papular phase to complete painless incrustation of lesions $(\mathrm{n}=121)$.

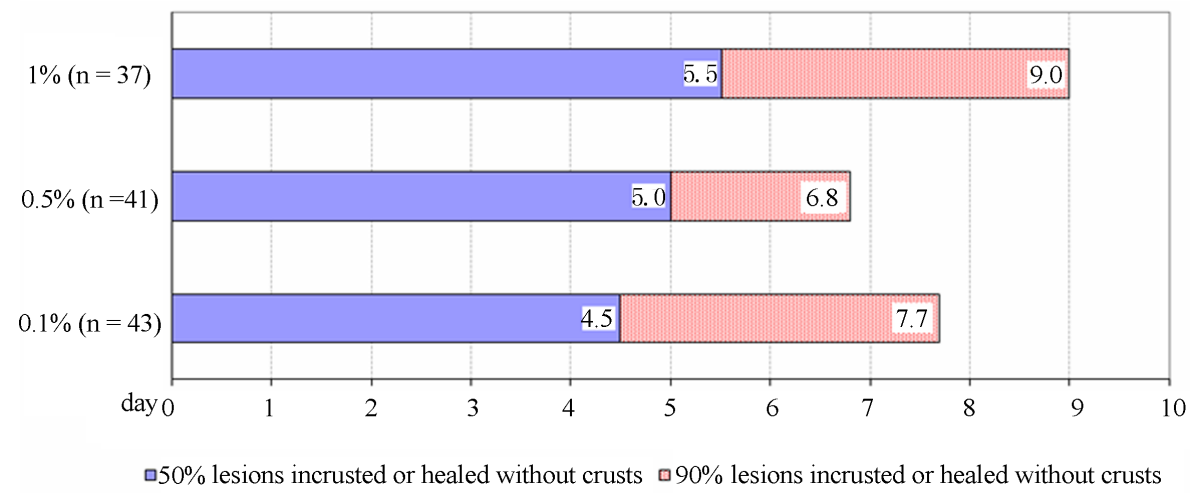

Figure 2. Time from prodromal phase to complete healing $(n=145)$.

was statistically significant (Kruskal-Wallis test: $\mathrm{p}=$ 0.006 and 0.05 ). The pair-wise analysis of treatment groups by the Mann-Whitney-test resulted in significant differences for the comparisons of the $0.1 \%$ and the $0.5 \%$ concentrations with the $1 \%$ concentration $(\mathrm{p}=$ 0.025 and 0.034 , respectively, for the comparison of $0.1 \%$ and $1.0 \% ; \mathrm{p}=0.002$ and 0.036 , respectively, for the comparison of $0.5 \%$ and $1.0 \%$ ), whereas significance was in both cases not reached for the comparison between treatments with 0.1 and $0.5 \%$ propolis extract.

\subsection{Secondary Parameters: Pain}

The secondary parameters pain, itching, swelling/tension and burning were assessed in all 145 patients. For all parameters a highly significant improvement was found on day 2/3 when values were compared with baseline (McNemar Test, in all cases $\mathrm{p}<5 \times 10^{-5}$ ). Due to the distinct improvement of symptoms on day $2 / 3$ these parameters were not further statistically investigated on study days 5/6 and 8/9. In no case a deterioration of the symptoms was observed after study day 2/3.

Pain reduction was fast, with distinct alleviation observed already few hours after the first application of the lip balm (data not shown). A highly significant reduction of pain was recorded with all three concentrations of active constituent. There was no statistically significant difference in the outcome of the various concentrations (covariance analysis; dependent variable VAS on day 2/3, $p=0.4$ ). Already on day $2 / 3$ the decrease of local pain had reached high statistical significance when compared with baseline values (paired t-test, $\mathrm{p}<10^{-8}$ in all groups). A reduction of VAS scores from baseline values of 65-70 to 15 units was observed on day 5/6 (Figure 3).

\subsection{Itching, Swelling/Tension and Burning}

The decrease of itching, swelling/tension and local burning was likewise highly significant in all three concentrations when compared with baseline values $(n=145$; McNemar's tests: $\mathrm{p}<5 \times 10^{-4}$ in all groups, Table $\mathbf{1}$ and Figure 4). The difference between groups was not significant with all three parameters $\left(\mathrm{Chi}^{2}\right.$-test by linear association, $p=0.34$ for itching, $p=0.4$ for tension/swelling and $\mathrm{p}=0.077$ for burning), but in each case an increasing percentage of patients with absent or mild complaints was associated with increasing dose.

\subsection{Assessment of Global Efficacy and Local Tolerability}

The assessment of global efficacy by the physician on 


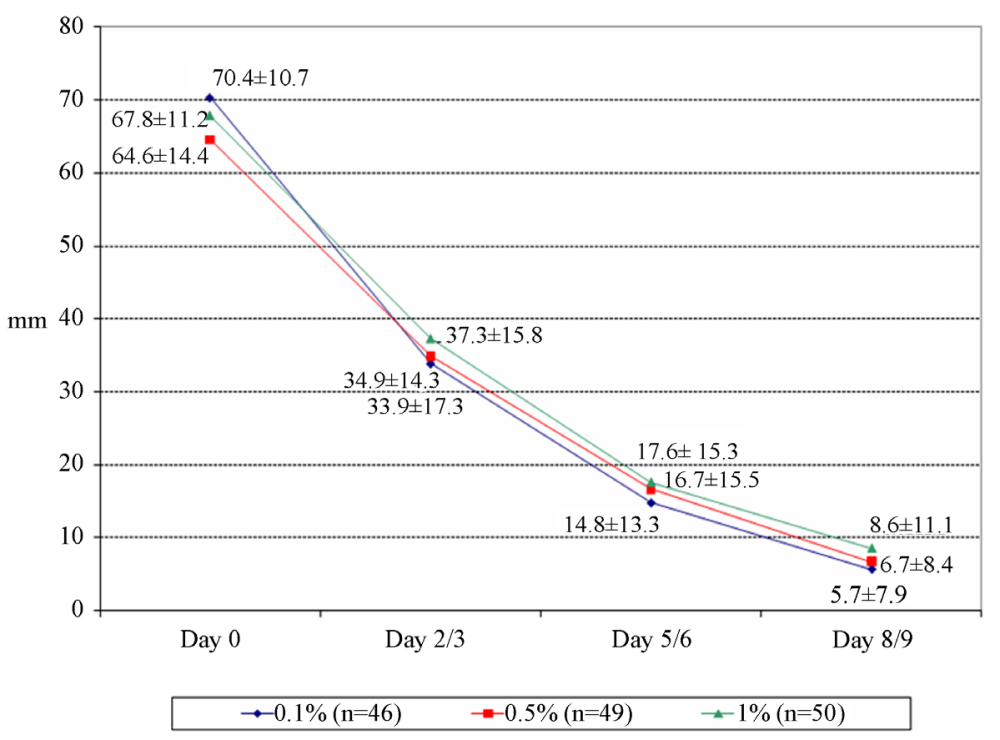

Figure 3. Effect of different concentrations of propolis extract on pain reduction in mm VAS $\left(\mathrm{n}=145\right.$, all results $\left.\mathrm{p}<10^{-8}\right)$.

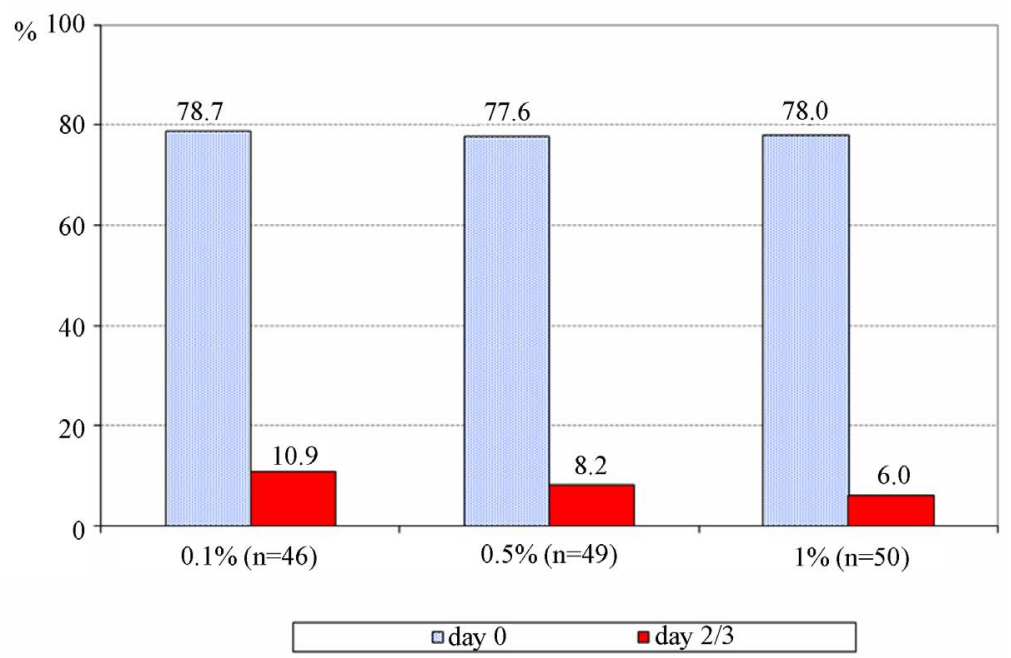

Figure 4. Effect of different concentrations of propolis extract on tension/swelling on study day 2/3 (Assessment by VRS): Percent of patients with moderate to severe symptoms $\left(n=145\right.$, all results $\left.\mathrm{p}<5 \times 10^{-4}\right)$.

study day 5/6 resulted in good and very good treatment effects in $80-89 \%$ of patients with all three concentrations. This finding is in line with the results from the evaluations

Table 1. Effect of different concentrations of propolis extract in the lip balm on itching, burning, and tension/swelling on study day 2/3 (Assessment by VRS). Percent of patients with moderate to severe symptoms $\left(n=145\right.$, all results $\left.\mathrm{p}<5 \times 10^{-4}\right)$.

\begin{tabular}{ccccccc}
\hline \multirow{2}{*}{ Dose } & \multicolumn{2}{c}{ Itching } & \multicolumn{2}{c}{ Burning } & \multicolumn{2}{c}{ Tension/swelling } \\
& Day 0 & Day 2/3 & Day 0 & Day 2/3 & Day 0 & Day 2/3 \\
\hline $0.1 \%$ & 87.0 & 26.1 & 74.5 & 17.4 & 78.7 & 10.9 \\
$0.5 \%$ & 87.8 & 22.4 & 59.2 & 10.2 & 77.6 & 8.2 \\
$1.0 \%$ & 83.3 & 18.0 & 66.0 & 6.0 & 78.0 & 6.0 \\
\hline
\end{tabular}

of the primary and secondary parameters.

On day 2/3 reversible local irritation was observed in one patient each of the $0.1 \%(n=48)$ and the $0.5 \%$-group $(n=50)$, and in 2 patients of the $1 \%$ group $(n=52)$. No local allergic reactions to propolis were encountered.

\section{DISCUSSION}

The aim of this study was to provide data justifying the choice of a defined dose scheme. Correspondingly, the primary statistical parameter used for the assessment was not the effect on the symptoms of Herpes labialis, but the statistically more reliable and reproducible calculation of the time to reaching the $50^{\text {th }}$ and 
$90^{\text {th }}$ percentile of healing until painless incrustation. This parameter allows an exact comparison of different treatments, and thus provides an answer to the question which concentration of propolis should be used in future research.

Despite the lack of a control group (placebo or reference) the study still provides information which allows concluding on a clinically important efficacy. The assessment of symptoms was addressed as secondary outcome parameters. These secondary parameters confirm the positive impact of propolis on the healing of Herpes labialis, and will be formally re-confirmed in a controlled clinical efficacy study.

The impact on healing time is clearly clinically important: The natural healing time of Herpes labialis to painless incrustation of usually $>8$ days can be reduced to approximately 6.5 days with the application of Aciclovir cream [30]. The application of a lip balm with propolis extract leads to a similar shortening of the Herpes episode (5.4 days in the $90^{\text {th }}$ percentile with $0.5 \%$ of extract in the preparation). Propolis is therefore confirmed to be a potent antiviral agent under clinical conditions.

Propolis special extract GH 2002 as an active constituent of a lip balm was effective against Herpes labialis in all three tested concentrations, $0.1 \%, 0.5 \%$ and $1 \%$. The size of the effect was comparable to the effect size observed in an earlier study, where we used an identical galenical preparation with $2 \%$ propolis extract (unpublished). The strong effect of the relatively low concentration of $0.1 \%$ active ingredient was surprising and retrospectively confirms the clinical importance of the potent antiviral effect observed in vitro [28,29]. In patients with Herpes labialis the application of lip balm with propolis extract leads to shortened healing times as compared with the natural untreated course of the Herpes episode [1,2].

Already after 2-3 days the secondary parameters pain, itching, tension/swelling and burning showed distinct improvements with all three extract concentrations. Pain reduction on study day 2-3 was especially remarkable, with a surprisingly rapid onset of effects reported only hours after the first application. The results from the assessment of the secondary parameters underline the beneficial contribution of additional pharmacological effects of propolis such as anti-inflammatory, woundhealing and antimicrobial properties, beyond the antiviral activity. For the patients such benefits clearly are clinically important.

The overall results of this study point to a concentration of $0.5 \%$ of propolis extract in the lip balm as the preparation with the best risk-benefit ratio. Healing times were shorter than with the $0.1 \%$-preparation which was expected -, but also significantly shorter than with $1 \%$ propolis extract, which was not expected, and is as yet unexplained. As a hypothesis, the better effect of the $0.5 \%$ concentration might be related to subclinical tolerability. As we had already observed an increased rate of skin irritation with the $2 \%$ concentration, it is possible that the $1 \%$ concentration still results in an increased rate of local irritation which is undistinguishable from the symptoms of Herpes labialis. This phenomenon would obviously no longer occur with the $0.5 \%$ dose, with no reduction of efficacy despite the lower dose.

With regard to safety of application, there was otherwise no difference between the two lower tested concentrations, with one observed case of local irritation both in the $0.1 \%(1 / 48,2.1 \%)$ and $0.5 \%$ groups $(1 / 50,2.0 \%)$. In the $1 \%$ group there were two cases $(2 / 52,3.9 \%)$. These findings are well comparable with those from treatment with aciclovir and pencilovir (2.0-3.8\% of patients) $[2,4,8]$. Furthermore, the results retrospectively confirm that the observation of an increased rate of local irritation with a preparation containing $2 \%$ of propolis extract were in fact dose-related. As the dose can be reduced without loss of antiviral efficacy, but with a remarkable gain in safety of application, future research will focus on the $0.5 \%$ concentration.

\section{REFERENCES}

[1] Patz, G. and Gross, G. (2006) Aciclovir Creme bei Lippenherpes. Dt Apoth Ztg, 145, 1653-1658.

[2] Spruance, S.L., Rea, T.L., Thoming, C., Tucker, R., Saltzman, R. and Boon, R. (1997) Penciclovir cream for the treatment of herpes simplex labialis. A randomized, multicenter, double-blind, placebo-controlled trial. Topical Penciclovir Collaborative Study Group, Journal of the American Medical Association, 277, 1374-1379.

[3] Spruance, S.L., Schnipper, L.E., Overall, J.C., Jr., Kern, E.R., Wester, B., Modlin, J., Wenerstrom, G., Burton, C., Arndt, K.A., Chiu, G.L. and Crumpacker, C.S. (1982) Treatment of herpes simplex labialis with topical acyclovir in polyethylene glycol. Journal of Infectious Diseases, 146, 85-90.

[4] Spruance, S.L., Nett, R., Marbury, T., Wolff, R., Johnson, J. and Spaulding, T. (2002) Acyclovir cream for treatment of herpes simplex labialis: results of two randomized, double-blind, vehicle-controlled, multicenter clinical trials. Antimicrobial Agents and Chemotherapy, 46, 2238-2243. doi:10.1128/AAC.46.7.2238-2243.2002

[5] Fiddian, A.P. and Ivanyi, L. (1983) Topical acyclovir in the management of recurrent herpes labialis. British Journal of Dermatology, 109, 321-326. doi:10.1111/j.1365-2133.1983.tb03548.x

[6] Raborn, G.W., McGaw, W.T., Grace, M., Percy, J. and Samuels, S. (1989) Herpes labialis treatment with acyclovir 5\% modified aqueous cream: a double-blind randomized trial. Oral Surgery, Oral Medicine, Oral Pathology, Oral Radiology, and Endodontology, 67, 676-679.

[7] Raborn, G.W., Martel, A.Y., Lassonde, M., Lewis, M.A., Boon, R. and Spruance, S.L. (2002) Effective treatment of herpes simplex labialis with penciclovir cream: Com- 
bined results of two trials. Journal of the American Dental Association, 133, 303-309.

[8] Boon, R., Goodman, J.J., Martinez, J., Marks, G.L., Gamble, M. and Welch, C. (2000) Penciclovir cream for the treatment of sunlight-induced herpes simplex labialis: a randomized, double-blind, placebo-controlled trial. Penciclovir Cream Herpes Labialis Study Group. Clinical Therapeutics, 22, 76-90. doi:10.1016/S0149-2918(00)87979-5

[9] Van Vloten, W.A., Swart, R.N. and Pot, F. (1983) Topical acyclovir therapy in patients with recurrent orofacial herpes simplex infections. Journal of Antimicrobial Chemotherapy, 12, 89-93.

[10] Morfin, F. and Thouvenot, D. (2003) Herpes simplex virus resistance to antiviral drugs. Journal of Clinical Virology, 26, 29-37. doi:10.1016/S1386-6532(02)00263-9

[11] Scheller, S., Scaflarski, J., Tustanowski, J., Nolewajka, E. and Stojke, A. (1977) Biological properties and clinical applications of propolis. Arzneimittel-Forschung/Drug Research, 27, 105-111.

[12] Langner, E. and Schilcher, H. (1999) Propolis. Dt Apoth Ztg, 139, 3447-3458.

[13] Kujumgiev, A., Tsetkova, I., Serkedjieva, J., Bankova, V.S., Christov, R. and Popov, S. (1999) Antibacterial, antifungal and antiviral activity of propolis of different geographic origin. Journal of Ethnopharmacology, 64, 235-240. doi:10.1016/S0378-8741(98)00131-7

[14] Burdock, G.A. (1998) Review of the biological properties and toxicity of bee propolis (propolis). Food and Chemical Toxicology, 36, 347-363. doi:10.1016/S0278-6915(97)00145-2

[15] Castaldo, S. and Capasso, F. (2002) Propolis, an old remedy used in modern medicine. Fitoterapia, 73, S1-S6. doi:10.1016/S0367-326X(02)00185-5

[16] Koo, H., Gomes, B.P., Rosalen, P.L., Ambrosano, G.M., Park, Y.K. and Cury, J.A. (2000) In vitro antimicrobial activity of propolis and Arnica montana against oral pathogens. Archives of Oral Biology, 45, 141-148. doi:10.1016/S0003-9969(99)00117-X

[17] Boyanova, L., Derejian, S., Koumanova, R., Katsarov, N., Gergova, G., Mitov, I., et al. (2003) Inhibition of Helicobacter pylori growth in vitro by Bulgarian propolis: Preliminary report. Journal of Medical Microbiology, 52, 417-419. doi:10.1099/jmm.0.04895-0

[18] Cafarchia, C., De Laurentis, N., Milillo, M.A., Losacco, V. and Puccini, V. (1999) Antifungal activity of Apulia region propolis. Parassitologia, 41, 587-590.

[19] Borrelli, F., Maffia, P., Pinto, L., Ianaro, A., Russo, A., Capasso, F. and Lalenti, A. (2002) Phytochemical compounds involved in the anti-inflammatory effect of prop- olis extract. Fitoterapia, 73, S53-S63. doi:10.1016/S0367-326X(02)00191-0

[20] Amoros, M., Simoes, C.M.O., Girre, L., Sauvager, F. and Cormier, M. (1992) Synergistic effects of flavons and flavonols against Herpes simplex virus type I in cell culture. Comparison with the antiviral activity of propolis. Journal of Natural Products, 55, 1732-1740. doi:10.1021/np50090a003

[21] Amoros, M., Lourton, E., Boustie, Y., Girre, L., Sauvager, F. and Cormier, M. (1994) Comparison of the anti-Herpes simplex virus activities of propolis and 3-methyl- but-2-enyl caffeate. Journal of Natural Products, 57, 644-647. doi:10.1021/np50107a013

[22] Debiaggi, M., Tateo, F., Pagani L., Luinni, M. and Romero, E. (1990) Effects of propolis flavonoids on virus infectivity and replication. Microbiologica (Italia), 13, 207-213.

[23] König, B. and Dustmann, H.J. (1988) Baumharze, Bienen und antivirale Chemotherapie. Naturwissenschaftliche Rundschau, 41, 43-53.

[24] Serkedjieva, J., Manolova, N. and Bankova, V.S. (1992) Anti-influenza virus effect of some propolis constituents and their analogues (esters of substituted cinnamic acids). Journal of Natural Products, 55, 294-297. doi:10.1021/np50081a003

[25] Thiel, K.-D., Wutzler, P., Helbig, B., Klöckning, R., Sprössig, M. and Schweizer, H. (1984) Antivirale Wirksamkeit von enzymatisch und nicht-enzymatisch oxidierter Kaffee- und Hydrokaffeesäure gegenüber Herpesvirus hominis Typ 1 und Typ 2 in vitro. Pharmazie, 39, 781-782.

[26] Vynograd, S., Vynograd, I. and Soznowski, Z. (2000) A comparative multi-centre study of the efficacy of propolis, acyclovir and placebo in the treatment of genital herpes (HSV). Phytomedicine, 7, 1-6.

[27] König, B. and Dustmann, H.J. (1985) The caffeoylics as a new family of natural antiviral compounds. Naturwissenschaften, 72, 659-661.doi:10.1007/BF00497441

[28] Nolkemper, S., Reichling, J., Sensch, K.H. and Schnitzler, P. (2010) Mechanism of herpes simplex virus type 2 suppression by propolis extracts. Phytomedicine, 17, 132-138. doi:10.1016/j.phymed.2009.07.006

[29] Schnitzler, P., Neuner, A., Nolkemper, S., Zundel, C., Nowack, H. and Sensch, K.H. (2010) Antiviral activity and mode of action of propolis extracts and selected compounds. Phytotherapy Research, 24, S20-S28.

[30] Saller, R., Buechi, S., Meyrat, R. and Schmidhauser, C. (2001) Combined herbal preparation for topical treatment of Herpes labialis. Forsch Komplementarmed Klass $\mathrm{Na}$ turheilkd, 8, 373-382. doi:10.1159/000057255 